\title{
Biodegradation of 2,4,6-Trinitrotoluene (TNT) with Bacteria Isolated from TNT-polluted Waste Pink Water
}

\author{
Zehra Gün Gök ${ }^{1 *}$, Murat İnal', Mustafa Yiğitoğlu \\ 1 Department of Bioengineering, Faculty of Engineering, Kırıkkale University, Yahsihan, 71450 Kırıkkale, Turkey \\ ${ }^{*}$ Corresponding author, e-mail: zzehragungok@gmail.com
}

Received: 02 November 2018, Accepted: 14 February 2019, Published online: 27 March 2019

\begin{abstract}
In this study, bacterial strains that can use TNT as a nitrogen source isolated from TNT contaminated pink water. We isolated 5 bacterial strains and the isolated bacteria were cultured in medium containing TNT and TNT degradation capacities of isolates were determined by spectrophotometric analysis. According to the results of the analysis that have done, 3 bacterial isolates that have high TNT degradation capacity were selected and the isolates were identified with firstly Gram-staining then with 16S rRNA sequence analysis method. According to the sequence of $16 \mathrm{~S}$ rRNA, water isolates were identified as Stenotrophomonas maltophilia (SU K2), Klebsiella pneumoniae (SU K3), Raoultella planticola (SU K4). During the TNT degradation studies, at the end of $24 \mathrm{~h}$ incubation time, in the medium containing 100 mg/L TNT, TNT degradation rate for SU K2, SU K3 and SU K4 were determined $70 \%, 96 \%$ and $93 \%$ respectively. 4-aminodinitrotoluene and 2-aminodinitrotoluene accumulations were detected in the culture medium of all isolates as intermediate products formed during the degradation of TNT by HPLC analysis. Additionally, nitrite accumulation was detected in the culture medium of all isolates and the influence of temperature and $\mathrm{pH}$ on the degradation of TNT was also investigated. It was determined that SU $\mathrm{K} 2$ isolates have the highest TNT degradation capacity at $35^{\circ} \mathrm{C}$, the others have at $30^{\circ} \mathrm{C}$ and all isolates degraded TNT fastest at pH 7 . The results of the study show that the new isolates can be useful for the removal of TNT in a wastewater treatment system.
\end{abstract}

Keywords

biodegradation, trinitrotoluene, contaminated water, isolation of bacteria

\section{Introduction}

Contamination of soil and ground water with explosives is a global challenge that started in World War I due to many military activities [1]. The most commonly used nitroaromatic explosive is TNT. TNT is a toxic chemical and it can remain in nature for a long time without degradation due to the symmetrical arrangement of the nitro groups in its structure [2]. In the World War II, TNT was manufactured prevalently and this large-scale manufacture of TNT in many explosive producing factory sites has led to contamination by TNT and its byproducts [3]. In typical TNT-contaminated areas, it is reported that the amount of TNT has been up to $10 \mathrm{~g} / \mathrm{kg}$ in the soil and to $100 \mathrm{mg} / \mathrm{L}$ in water [4]. However, today, TNT pollution does not originate just from tons of TNT produced in the first and second world wars. During the demilitarisation of the munitions prepared by the use of TNT as an explosive, pink water known to contain TNT and other explosives is released [5]. The presence of pink water is based on photolysis of dissolved TNT and the collection of complex dye-like molecules [6]. TNT and its associated explosive compounds cause pollution if this water is delivered to the soil without purification [5]. TNT contamination from TNT-containing pink water in military regions has also been reported by researchers in the literature $[5,7]$. Chusova et al. [5] collected TNT contaminated pink water released from a treatment plant at the demilitarisation factory Nammo Vingakersverken $\mathrm{AB}$ and they stated that the TNT level in the pink water was $12 \mathrm{mM}$ after serial dilutions (5 times) and removing of the insoluble components. Eum et al. [7] collected pink water from Agency for Defense Development, Daejeon, Korea for researching the effects of TNT-contaminated pink water in Zebrafish embryogenesis. They stated that the amount of TNT in the pink water was $45.54 \mathrm{mg} / \mathrm{L}$.

TNT is an important environmental pollutant with toxic effects on many organisms, including humans [4]. 
Due to the TNT pollution levels in nature, TNT is classified as a worrying xenobiotic chemical. TNT has high solubility in water compared to other nitroaromatic compounds and thus causes pollution of both soil and groundwater in nature [2]. People may be exposed to TNT contamination directly with contaminated water or indirectly if they are fed with agricultural products grown in soil contaminated with TNT. Blood, liver and reproductive systems of people exposed to TNT pollution are affected by the toxic effects of TNT [8]. Environmentally friendly treatment methods need to be developed in order to eliminate the negative effects of TNT pollution on humans and ecosystems. Several physicochemical methods have been developed for cleaning contaminated areas with TNT, but these have disadvantages such as the formation of undesirable greenhouse gases and new environmental waste or being costly $[4,9]$. For these reasons, recent research has focused on bioremediation processes, which are biological based processes in which living organisms (mostly microorganisms) are used to remove pollutants from the environment, which have the advantages of being environmentally friendly and cost-effective in clearing the regions exposed to TNT pollution [10].

There are many synthetic materials produced by people which did not exist before in nature and these chemicals have been used by microorganisms as carbon and energy sources [11]. TNT is also a synthetic chemical that can be metabolized by microorganisms and aerobic-anaerobic bacteria can degrade TNT with their nitroreductase enzymes. The bacteria use TNT as a nitrogen source and reduce it to hydroxyl-aminodinitrotoluenes (HADNT), aminodinitrotoluenes (ADNT), diaminomononitrotoluenes (DAMNT) and dinitrotoluenes (DNT) [2].

In this work, the bacterial strains that can used to remediate the TNT contaminated pink water and sites isolated from TNT polluted pink water at military sites in Kırıkkale, Turkey. Then, the bacterial TNT degradation capacities, degradation products and effects of $\mathrm{pH}$ and temperature on TNT degradation by the isolates were investigated.

\section{Experimental Section \\ 2.1 Chemicals}

For isolation and incubation of bacteria, nutrient broth, nutrient agar and plate count agar were purchased from Biokar Diagnostics, France. For HPLC analysis, the analytical grade standards of 2-ADNT, 4-ADNT were taken from Cerilliant (USA) and 2,6-DNT, 2,4-DNT standards were purchased from Fluka (USA). TNT was obtained from The Machinery and Chemical Industry Institution (Kırıkkale, Turkey). All other chemicals were taken Sigma-Aldrich and used without any purifications.

Pink water is defined as wastewater generated during the packaging and disposal of TNT [12]. For this reason, water sample for isolation of bacteria was collected from visible color change pinkish waters [6].

\subsection{Culture condition and isolation of microorganisms}

For bacterial isolation from the pink water sample contaminated with TNT, $1 \mathrm{~mL}$ of water was homogenized with $9 \mathrm{~mL}$ of sterile water and the mixture was left to stand at room temperature to rinse the supernatant. The supernatant was inoculated into $100 \mathrm{~mL}$ of TNT degrading medium (containing 6/L Na $\mathrm{NPO}_{4}, 3 \mathrm{~g} / \mathrm{L} \mathrm{KH}_{2} \mathrm{PO}_{4}, 0.5$ $\mathrm{g} / \mathrm{L} \mathrm{NaCI}, 0.24 \mathrm{~g} / \mathrm{L} \mathrm{MgSO}_{4}, 10 \mathrm{~g} / \mathrm{L}$ glucose and $0.1 \mathrm{~g} / \mathrm{L}$ TNT) prepared according to Gümüşçü and Tekinay [6] with some modifications. After various dilutions, and the flakes were incubated under aerobic conditions at $30^{\circ} \mathrm{C}$. After 3 days of incubation, inoculants that could grow in medium containing only TNT as a nitrogen source were transferred to the fresh medium. The bacterial cultures obtained were inoculated on nutrient agar and incubated at $30{ }^{\circ} \mathrm{C}$. Following incubation, colonies that were distinct and morphologically different on solid media were selected and isolated as pure culture. A total of 5 bacterial isolates were obtained from the water sample contaminated with TNT.

Glycerol stock solutions were prepared to store the isolated colonies at $-80^{\circ} \mathrm{C}$. Single colonies of bacterial cultures isolated from TNT medium were transferred to solid medium and stored in refrigerator at $+4{ }^{\circ} \mathrm{C}$ and transferred to fresh solid medium every 3 months. Subsequent studies were continued with 5 bacterial strains isolated from the sample.

\subsection{Selecting of high TNT degrading bacteria and identification of the selected microorganisms}

All isolates were cultured in the basal medium containing TNT only as a nitrogen source for determination of TNT degradation capacities of the isolates and TNT degradation capacity of each isolate was determined by determining TNT amount of samples taken from the medium at regular intervals. Before the incubation of the isolates in TNT degradation medium, the bacterial cells were cultured overnight at $30^{\circ} \mathrm{C}$ in the nutrient broth (until the absorbance at $600 \mathrm{~nm}$ was $\sim 1.5$ and cell numbers were $\sim 10^{8}$ 
cells $/ \mathrm{mL}$ ) and $2 \%$ inoculum from these cultures (v/v) was transferred to $100 \mathrm{~mL}$ of TNT degradation medium. At the end of 1, 3 and 7 days of incubation, TNT was determined by spectrophotometric analysis. For spectrophotometric analysis of TNT, after obtaining of supernatant of the culture mediums, $1 \mathrm{~mL}$ of $1 \mathrm{M} \mathrm{KOH}$ was added and mixed to $5 \mathrm{~mL}$ of the supernatant, the amount of TNT in the solution was found out by measuring absorbance at $447 \mathrm{~nm}$ after $5 \mathrm{~min}$ from the addition of $\mathrm{KOH}$ solution to the supernatant $[13,14]$. The growth of bacteria during TNT degradation was monitored by optical density measurement at a wavelength of $600 \mathrm{~nm}$. Among the isolated bacteria, 3 bacterial strains with the highest TNT degradation capacity were selected for further studies.

Firstly, gram staining was performed to identify the selected bacterial isolates. Species of the selected isolated were determined with the 16S rRNA sequence analysis method [6, 15] in Molecular Biology Research Laboratory in Gazi University Life Sciences Research and Application Center.

\subsection{Biodegradation of TNT}

To determine TNT degradation rates of the bacterial isolates that have high TNT degradation capacity under aerobic conditions within 24-h incubation period, isolates were cultured in the basal medium containing TNT as a nitrogen source, bacterial growth was monitored by optical density measurements at a wavelength of $600 \mathrm{~nm}$. The amount of TNT in the medium was determined by spectrophotometric analysis of samples taken from the medium at regular intervals (every 4 hour). Before culturing the isolates in TNT containing medium, the isolates were incubated overnight at $30{ }^{\circ} \mathrm{C}$ in nutrient broth rate (until the absorbance at $600 \mathrm{~nm}$ were $\sim 1.5$ and cell numbers were $10^{8}$ cells $\left./ \mathrm{mL}\right) .2 \%$ inoculum $(\mathrm{v} / \mathrm{v})$ was transferred to $100 \mathrm{~mL}$ TNT medium. The isolates were incubated for 24 hour in the dark at $30{ }^{\circ} \mathrm{C}$ and $120 \mathrm{rpm}$ shaking rate under aerobic conditions. After incubation, at every $4 \mathrm{~h}$, the sample taken from the culture medium was centrifuged (15 min, 10000xg) and after removal of the cells, the amount of TNT in the liquid fraction was determined by the above-mentioned method.

\subsection{Determination of transformation metabolites}

The degradation products of TNT in the medium were analyzed by HPLC. For analysis of the degradation products, isolates were incubated in the TNT containing medium and after $24 \mathrm{~h}$ of incubation, samples from bacterial cultures were centrifuged and $1.5 \mathrm{~mL}$ of supernatants were mixed with $3.5 \mathrm{~mL}$ of methanol to for the analysis. For HPLC analysis, $10 \mu \mathrm{L}$ samples were injected into the Ultra Aromax column (150 mmx $4.6 \mathrm{~mm}, 5 \mu \mathrm{m}$, Restek Corporation, Bellefonte, PA, USA, Cat. No. 9127565) with a flow rate $1.2 \mathrm{~mL} / \mathrm{min}$ at $35^{\circ} \mathrm{C}$. The solvent system consisting of $30 \%$ deionized water and $70 \%$ methanol (v/v) was used as the mobile phase. The retention times of the degradation products were determined by the UV detector at $210 \mathrm{~nm}$ and the amounts of the products were determined by comparison with the standards.

\subsection{Determination of release of nitrite and ammonium ions}

During the growth of microorganisms in TNT containing medium, the amounts of nitrite and ammonium ion released in the culture medium to monitor denaturation of TNT were determined using Spectroquant test kits (Merck, Germany). The isolates were inoculated to the medium containing TNT, the samples were taken from the culture medium of the isolates at every $4 \mathrm{~h}$ and the samples were centrifuged at $10000 \mathrm{xg}$ for 15 minutes to remove the cells. The supernatant was used to determine the amounts of nitrite and ammonium. For nitrite testing, $5 \mathrm{~mL}$ of the supernatant was added to the tube containing Reagent $\mathrm{NO}_{2}-1$ and the mixture was sonicated until the reagent was completely dissolved. The $\mathrm{pH}$ of the solution was checked using a $\mathrm{pH}$ indicator paper and adjusted to 2-2.5 with $1 \mathrm{M} \mathrm{HCl}$. The absorbance of the pink solution formed after $10 \mathrm{~min}$ was measured against water at 525 nm wavelength. The measured absorbance value was multiplied by the factor found in the kit protocol and the nitrite content of the solution was calculated. For the ammonium test, $0.6 \mathrm{~mL}$ of Reagent $\mathrm{NH}_{4}-1$ and Reagent $\mathrm{NH}_{4}-2$ were added to $5 \mathrm{~mL}$ of supernatant and the solution was stirred until Reagent $\mathrm{NH}_{4}-2$ was completely dissolved. The mixture was incubated at room temperature for 5 minutes and then 4 drops of Reagent $\mathrm{NH}_{4}-3$ were added to the mixture. After the mixture was incubated again for 5 minutes, the absorbance of the solution was measured at $690 \mathrm{~nm}$. The measured absorbance value was multiplied by the factor to determine the $\mathrm{NH}_{4}^{+}$amount of the solution.

\subsection{Optimization of temperature and $\mathrm{pH}$ to TNT degradation}

To investigate the effect of temperature on the biodegradation of TNT, the isolates were incubated at $20^{\circ} \mathrm{C}, 25^{\circ} \mathrm{C}$, $30{ }^{\circ} \mathrm{C}, 35^{\circ} \mathrm{C}$ and $40^{\circ} \mathrm{C}$ incubation temperatures at $\mathrm{pH} 7$ for 
$24 \mathrm{~h}$ at $120 \mathrm{rpm}$ in TNT degradation medium. After $24 \mathrm{~h}$, TNT amount in the culture mediums was analyzed. The optimal incubation temperature for each isolate was determined according to the TNT degradation rate and bacterial growth. To determine the effect of $\mathrm{pH}$ on the TNT degradation by the isolates, the $\mathrm{pH}$ of the TNT degradation mediums was adjusted to $5,6,7,8,9$ with $1 \mathrm{M} \mathrm{HCl}$ and $1 \mathrm{M} \mathrm{NaOH}$, and the isolated were incubated overnight at $30^{\circ} \mathrm{C}$. The TNT amounts of the samples taken from the medium after $24 \mathrm{~h}$ were analyzed. The optimal $\mathrm{pH}$ value for each isolate was determined according to the results of TNT degradation rate and bacterial growth.

\section{Results and Discussion}

\subsection{Isolation and identification of microorganisms}

In recent years, TNT contamination levels have reached $200 \mathrm{~g} / \mathrm{kg}$ in soil and water in Europe and America [16]. In Turkey, there are also some studies in which TNT contamination levels were documented. In a study published by Gümüş̧̧ü and Tekinay [6], it was determined that the amounts of TNT in soil and water samples taken from Elmadağ region of Ankara was in the range of $20-245 \mathrm{mg} /$ $\mathrm{kg}$. In another study published by Mercimek et al. [17], the amount of TNT in the sample taken from the NATO region in Izmir, Turkey was determined as $61.35 \mathrm{mg} / \mathrm{L}$. The amount of TNT in the water sample taken for bacterial isolation was determined to be $134 \mathrm{mg} / \mathrm{kg}$ and TNT contamination of the sample was found to be between the limits specified in the literature.

Microorganisms were isolated from the water sample using the basal medium containing TNT a sole nitrogen source. Totally, 5 bacteria were isolated from the sample and 3 of them showed high TNT degradation capacity compared to the others. The isolated bacteria were named as $\mathrm{SU}$ K1, SU K2, SU K3, SU K4 and SU K5. In the experiments, the SU K1 and SU K5 isolates were found to have $59 \%$ and $39 \%$ TNT degradation capacity after $24 \mathrm{~h}$ of incubation period, respectively. It was determined that the TNT degradation capacity of other isolates was above $70 \%$. SU $\mathrm{K} 5$ has not been selected for further studies since it had low TNT degradation capacity compared to other bacteria and SU K1, although had close TNT degradation capacity to SU K2, has not been selected for further studies since this bacterium grew hardly in TNT degradation medium and in a standard media such as nutrient broth. Since SU K1 grew very slowly in the medium containing TNT, it is difficult to use it for practical remediation applications. In addition, we found that the amount of TNT remaining in culture medium was completely depleted for SU K3 at 7 days. For the other isolates, the amount of TNT remaining in culture medium was found to be $23.5 \mathrm{mg} / \mathrm{L}$ for SU K1, $16.3 \mathrm{mg} / \mathrm{L}$ for SU K2, $4 \mathrm{mg} / \mathrm{L}$ for SU K4 and $51.1 \mathrm{mg} / \mathrm{L}$ for SU K5 at 7 days (Supplementary Fig. 1). SU K2, SU K3 and SU K4 were selected for forward studies and the selected bacterial strains were able to grow in the presence of $100 \mathrm{mg} / \mathrm{L}$ TNT whereas this TNT concentration is toxic for many microorganisms [18]. Since the bacterial strains obtained in this study have been isolated from sample known to has been exposed to TNT contamination for many years, they are able to use TNT as a nitrogen source.

The first identification of the isolated bacteria was made according to the gram staining procedure, because, the purity of the isolates was determined by gram staining. For identification of the isolates by 16S rRNA sequence analysis, genomic DNAs of bacteria grown in nutrient broth were isolated, all 16S rRNA genes of each isolate were amplified by PCR and DNA sequence analysis of the PCR products was performed. The sequences obtained from the isolates were matched with the results of NCBI Gen Bank and microbial identification of the isolates were made according to the 16S rRNA gene sequence of each bacterium. The similarity of the sequences obtained from the isolates after gene blasting with gene bank results was indicated in Table 1. According to $16 \mathrm{~S}$ rRNA sequence analysis, SU K2, SU K3 and SU K4 isolates were identified as $S$. maltophilia, K. pneumoniae and R. planticola respectively. The degradation of TNT with $S$. maltophilia, Klebsiella sp. and R. planticola has also been reported by other investigators in the literature [19-21] S. maltophilia is an aerobic, nonfermentative, Gram-negative bacterium. It is possible to encounter this bacterium in various environments (such as water, plants and hospital). Although, it is a pathogen and one of the many antibiotic resistant nosocomial infectious agents, the researches have demonstrated a potential role for this bacterium in biotechnology. It has been utilized as biological control agent against fungal plant pathogens in agriculture and in bioremediation [22]. $K$. pneumoniae is Gram-negative, non-spontaneous and

Table 1 According to the NCBI GenBank results, the similarities of 16S rRNA sequences obtained with the UNI27F/1492R primer from the isolates

\begin{tabular}{cccc}
\hline Isolate & Identification Results & Gen Bank No & Homology(\%) \\
\hline SU K2 & S. maltophilia & KJ584896.1 & $98 \%$ \\
SU K3 & K. pneumoniae & KM096433.1 & $99 \%$ \\
SU K4 & R. planticola & JX294892.1 & $99 \%$ \\
\hline
\end{tabular}


fermentative bacterium. Although, it is found in normal flora, in the mouth, skin and intestine, it causes destructive damage in the lung, if aspirated [23]. K. pneumoniae is a pathogen strain with the potential to be used as a biological warfare agent [24]. In addition, there are studies in the literature on the synthesis of many valuable chemicals with this bacterium $[25,26]$. R. planticola is a gram-negative and aerobic bacterium commonly existed in the environment, especially in water and soil. This microorganism has been found to induce a various type of infections, such a, pancreatitis and soft tissue infections. However, human infections due to by $R$. planticola are infrequently reported [27]. In addition, there are studies showing that this strain has potential to be used in bioremediation studies $[21,28]$.

\subsection{TNT degrading experiments}

In this study, TNT was effectively degraded by the bacteria obtained from the TNT contaminated pink water. After the selection of the best TNT metabolizing strains, the strains were incubated TNT containing medium, the microbial degradation of TNT was monitored with the sample taken at regular intervals within $24 \mathrm{~h}$ from the bacterial cultures whereas the turbidity was measured at $600 \mathrm{~nm}$ every $4 \mathrm{~h}$ for bacterial growth monitoring.

Fig. 1 shows the optical density versus TNT amount in bacterial cultures and control group. For all isolates, the amount of TNT in the culture medium decreased with time, bacterial growth was found to be increased and this result was found to be consistent with the previous studies [6, $29,30]$. The isolates started to use TNT as a nitrogen source immediately after being inoculated in TNT containing medium and at the end of the first $4 \mathrm{~h}$ incubation period, all isolates began to metabolize TNT as previously mentioned by Gümüşçü and Tekinay [6]. It was determined that the water isolates have the capacity to break the initial TNT by $70-96 \%$ at the end of the $24 \mathrm{~h}$ incubation period. SU K2 isolate was found to be the least capable of degrading TNT and had the lowest growth ability. SU K2 degraded $70 \%$ of the initial TNT at the end of the 24-hour incubation period. SU K3 and SU K4 isolates had high TNT degradation capacity compared to SU K2 and it was determined that the isolates


Time (h)

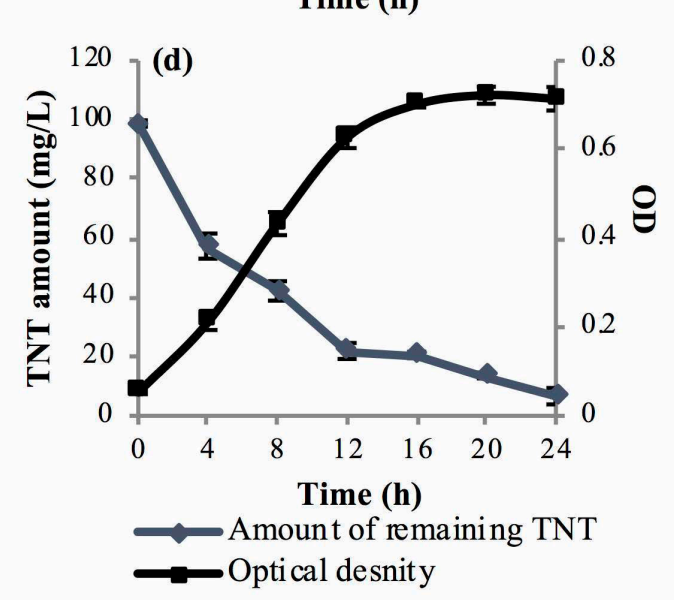

Fig. 1 TNT amount versus bactarial growth (OD-optical desnity) in cultures of Control (sterile medium) (a), SU K2 (b), SU K3 (c) and SU K4 (d) at $30{ }^{\circ} \mathrm{C}$ in TNT degradation medium (Experiments were done in 3 replicates, results were given as mean and error bars were indicated in the graphics) 
degraded $96 \%$ and $93 \%$ of the initial TNT respectively at the end of the 24-h incubation period. Since, the isolates were selected according to their ability, the resulting bacterial isolates increased cell biomass in the presence of 100 $\mathrm{mg} / \mathrm{L} \mathrm{TNT}$ and degraded the initial TNT at rates ranging from $70 \%$ to $96 \%$ within $24 \mathrm{~h}$. Compared to previous TNT degradation studies in the literature, these degradation rates were observed to be quite high $[17,30]$.

The sterilized TNT degradation medium which was not inoculated with bacteria was used as control group and TNT decrease was not detected at the end of 24 hour incubation period in the control groups (Fig. 1(a)). A significant TNT degradation was observed in all bacterial cultures compared to the control group.

\subsection{Analysis of degradation metabolites}

At the end of the 24-h incubation period from the bacterial cultures, the degradation samples were analyzed by HPLC and the products formed as a result of microbial decomposition of TNT were identified. According to the results of the HPLC analysis, TNT, 2-ADNT and 4-ADNT amounts of the isolates in the TNT degradation medium before the inoculations (0th hour) and $24 \mathrm{~h}$ after the inoculations were given in Table 2. According to the results of HPLC analysis, 4-ADNT and 2-ADNT accumulations were determined in bacterial cultures of all isolates whereas DNT accumulation was not detected in any cultures. In many studies on microbial degradation of TNT, it has been reported that these intermediates are formed due to bacterial transformation, and these results are consistent with the findings of previous studies [6, 17, 29]. Conversion of TNT to 4-ADNT and 2-ADNT compounds is desirable to eliminate the toxic effects of TNT because the toxic effects of the 4-ADNT and 2-ADNT nitroaromatic compounds are less than TNT, their solubility in water is lower than TNT and they have no explosive properties [31].

\subsection{Accumulation of nitrite and ammonium ions}

The release of nitrite ions from TNT and ammonium ions from the HADNT (intermediate TNT degradation product) indicates the microbial degradation of TNT [32]. The accumulations of these ions in the culture of the isolates during TNT degradation were given in Fig. 2. As shown in Fig. 2(a), the nitrite level increased rapidly between 0 and $24 \mathrm{~h}$ and reached to $2 \mathrm{mg} / \mathrm{L}$ at the end of the $24 \mathrm{~h}$ in the culture of SU K2. The amount of ammonium was almost constant between 0 and $20 \mathrm{~h}$, but it was found to
Table 2 The amount of TNT, 2-ADNT and 4-ADNT in bacterial cultures before incubation and $24 \mathrm{~h}$ after incubation period

\begin{tabular}{lcccccc}
\hline & \multicolumn{3}{c}{ 0th hour } & \multicolumn{3}{c}{ 24th hour } \\
\hline Isolates & $\begin{array}{c}\text { TNT } \\
(\mathrm{mg} / \mathrm{L})\end{array}$ & $\begin{array}{c}\text { 2-ADNT } \\
(\mathrm{mg} / \mathrm{L})\end{array}$ & $\begin{array}{c}\text { 4-ADNT } \\
(\mathrm{mg} / \mathrm{L})\end{array}$ & $\begin{array}{c}\text { TNT } \\
(\mathrm{mg} / \mathrm{L})\end{array}$ & $\begin{array}{c}\text { 2-ADNT } \\
(\mathrm{mg} / \mathrm{L})\end{array}$ & $\begin{array}{c}\text { 4-ADNT } \\
(\mathrm{mg} / \mathrm{L})\end{array}$ \\
\hline SU K2 & 101.1 & 0 & 0 & 18.2 & 2.6 & 12.6 \\
SU K3 & 101.0 & 0 & 0 & 4.13 & 2.3 & 11.2 \\
SU K4 & 102.7 & 0 & 0 & 6.73 & 2.62 & 12.1 \\
\hline
\end{tabular}

decrease to $0.107 \mathrm{mg} / \mathrm{L}$ at the end of $24 \mathrm{~h}$. Although SU K2 had the lowest TNT degradation capacity among the selected isolates, the highest amount of nitrite accumulation was detected in the culture of SU K2. This can be explained by the fact that SU K2 has a different TNT degradation mechanism or it cannot use released nitrite ions from bacterial degradation of TNT as effectively as other isolates for metabolic activities. The Meisenheimer complex formed by the reduction of TNT by microorganisms causes the formation of red-brownish color in bacterial cultures and the release of nitrite ions [17]. In TNT degradation studies, this color formation was observed in cultures of SU K2 isolate whereas it was not observed in the cultures of other isolates and in the control group. This color change and the release of nitrite ions indicate that this isolate degrades TNT by forming a Meisenheimer complex as reported in the previous study [17]. As shown in Fig. 2 (b), (c) for SU K3 and SU K4 isolates, after the inoculation of bacteria, the amount of nitrite and ammonium changed according to the initial values after the inoculation and reached their maximum level after $4 \mathrm{~h}$. These results showed that TNT was subjected to bacterial breakdown [29]. In all isolates cultures, more than $40 \%$ of the initial TNT was degraded during the first $4 \mathrm{~h}$ of incubation. Therefore, at the end of the first $4 \mathrm{~h}$ of incubation period, the amount of nitrite and ammonium reached their maximum level, and then there was a decrease in the amount of the ions accumulated in the medium because they were used as a nitrogen source by the bacterial cells.

To sum up, nitrite and ammonium deposits were determined in all bacterial cultures between 0 and $24 \mathrm{~h}$. Since, there is no nitrogen-containing compound in the medium where the isolates are cultured, nitrite and ammonium accumulation in the culture medium indicate that the water isolates are capable of breaking down TNT. In the literature, several studies support our results for nitrite and ammonium accumulation during the breakdown of TNT with different microorganisms $[6,17,29]$. 

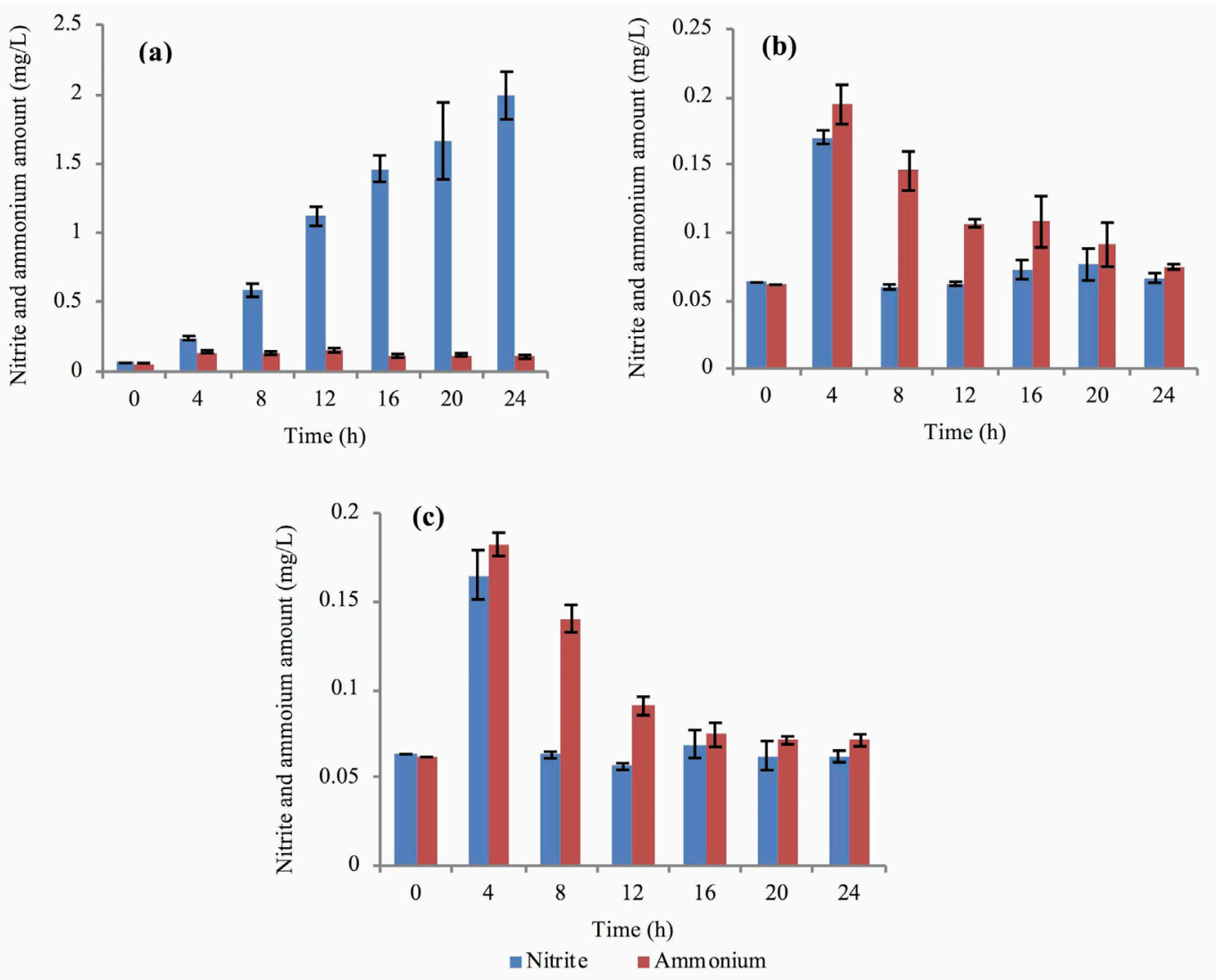

Fig. 2 Changes of $\mathrm{NO}_{2}^{-}$and $\mathrm{NH}_{4}^{+}$amounts in culture media during degradation of TNT in SU K2 (a), SU K3 (b) and SU K4 (c) cultures (Experiments were done in 3 replicates, results were given as mean and error bars were indicated in the graphics)

\subsection{Temperature and $\mathrm{pH}$ effects on TNT degradation by the isolates}

The degradation of organic pollutants by microorganisms depends on environmental conditions such as temperature, medium components and $\mathrm{pH}$ [33]. Since, the growth of most microorganisms is sensitive to $\mathrm{pH}$ and temperature change, the TNT degradation capacity of the strains was tested at several $\mathrm{pH}$ and temperature values to determine optimal conditions for the bacterial growth and TNT remediation. The $\mathrm{pH}$ and temperature range selected in the study were determined based on previous studies on TNT degradation $[6,9]$. TNT degradation rates varying at different temperatures for water isolates were given in Fig. 3.

The $\mathrm{pH}$ of the culture medium significantly influences bacterial growth [13], so that the degradation of TNT with isolates was performed at different $\mathrm{pH}$ values to investigate the effect of $\mathrm{H}^{+}$concentration on TNT degradation rates. TNT degradation rates varying at different $\mathrm{pH}$ for water isolates were given in Fig. 4. During the degradation studies, a sample was taken from degradation medium at every $4 \mathrm{~h}$, the $\mathrm{pH}$ of the degradation medium was checked with $\mathrm{pH}$ indicator papers and no significant change in the $\mathrm{pH}$ of the buffer solution (initially adjusted to desired $\mathrm{pH}$ ) during the experiments was observed. As shown in Fig. 3 and 4, the ability of all isolates to degrade TNT varied at different temperature and $\mathrm{pH}$ values. In previous TNT degradation studies performed with SU K2 isolate, TNT degradation rate at the end of $24 \mathrm{~h}$ incubation period was determined to be $70 \%$ at $30{ }^{\circ} \mathrm{C}$. In the TNT degradation studies performed at different temperatures, it was determined that the maximum TNT degradation capacity of this isolate was at $35^{\circ} \mathrm{C}$ and the TNT degradation rate at this temperature was $82 \%$. In the TNT degradation studies performed with SU K3 isolate, it was determined that the rate of degradation of TNT of the isolate was maximum at $30{ }^{\circ} \mathrm{C}$ at the end of the $24 \mathrm{~h}$ incubation period and decreased from $96 \%$ to $80-90 \%$ when the temperature increased or decreased. In the biological TNT degradation experiments with SU $\mathrm{K} 4$ isolate, the rate of TNT degradation of the isolate did not change and at $30^{\circ} \mathrm{C}$ and $35^{\circ} \mathrm{C}$ and the TNT degradation capacity of the isolate decreased when the temperature became 20, 25 and $40{ }^{\circ} \mathrm{C}$. SU K2 and SU K4 bacteria were affected by temperature change more than SU K3 and TNT degradation capacities of them varied depending on the incubation temperature. This change was especially seen at $20^{\circ} \mathrm{C}$ and the TNT degradation capacity of 

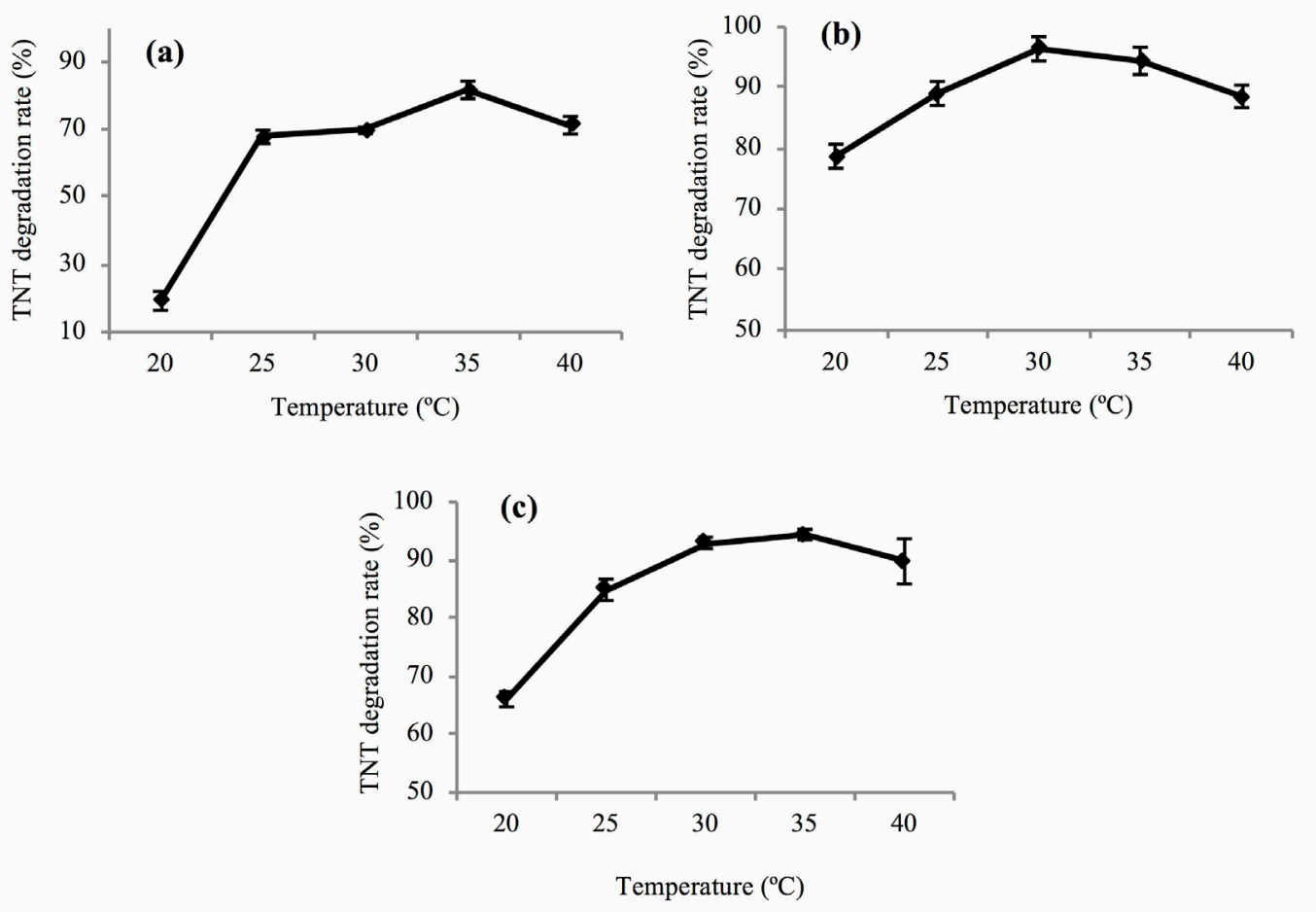

Fig. 3 Effect of temperature on TNT degradation by the SU K2 (a), SU K3 and SU K4 isolate (at pH 7) (Experiments were done in 3 replicates, results were given as mean and error bars were indicated in the graphics)
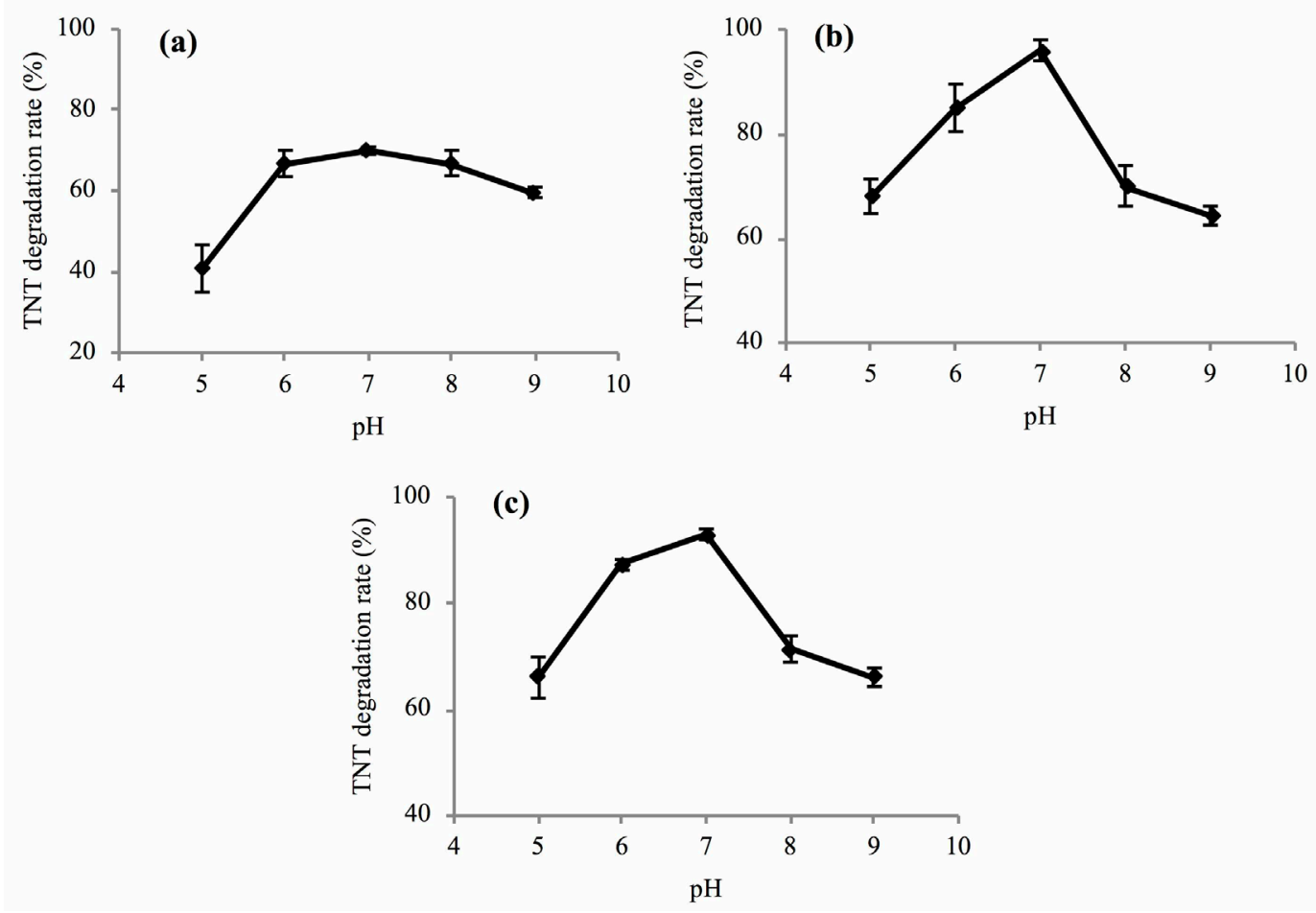

Fig. 4 Effect of pH on TNT degradation by the SU K2 (a), SU K3 and SU K4 isolate (at $30^{\circ} \mathrm{C}$ ) (Experiments were done in 3 replicates, results were given as mean and error bars were indicated in the graphics) 
SU K2 and SU K4 decreased to $20 \%$ and $65 \%$, respectively. SU K3 was more resistant to temperature changes than the other isolates and TNT degradation capacity did not fall below $80 \%$ in a wider range of temperature. All isolates were found to have maximum TNT degradation capacity at $\mathrm{pH} 7$ and the TNT degradation capacity of the isolates was found to be reduced in more alkaline or acidic conditions. These results were in conformity with previous studies $[10,11]$. However, at different $\mathrm{pH}$ values, SU $\mathrm{K} 2$ isolate was not affected by change in incubation $\mathrm{pH}$ as well as the other isolates. From these results, it was seen that $\mathrm{SU}$ K2 seemed to work in a wider range of $\mathrm{pH}$ while SU K3 and SU K4 were not really tolerant of changes. The findings demonstrated that by investigating the effect of temperature and $\mathrm{pH}$ on TNT degradation, which is one of the important environmental factors in the development of microorganisms, the degradation of TNT can be improved.

\section{Conclusion}

During the first and second world wars, TNT was widely used as an explosive material and the contamination of soil and groundwater with TNT caused an environmental problem that has continued to this day [34]. Traditional methods such as combustion and thermal oxidation, which are used to eliminate TNT pollution in many military regions are extremely expensive and destructive processes and cause undesirable greenhouse gases [4]. In recent

\section{References}

[1] Hawari, J., Beaudet, S., Halasz, A., Thiboutot, S., Ampleman, G. "Microbial degradation of explosives: biotransformation versus mineralization", Applied and Environmental Microbiology, 54, pp. 605618, 2000. [online] Available at: https://link.springer.com/content/ pdf/10.1007/s002530000445.pdf [Accessed: 14 October 2018]

[2] Esteve-Nuñez, A., Caballero, A., Ramos, J. L. "Biological Degradation of 2,4,6-Trinitrotoluene", Microbiology and Molecular Biology Reviews, 65, pp. 335-352, 2001. https://doi.org/10.1128/MMBR.65.3.335-352.2001

[3] Haselhorst, L. "Bioremediation of 2,4,6-Trinitrotoluene (TNT) at munitions sites", Restoration and Reclamination Rewiew, 4 (7), pp. 1-9, 1999. [online]. Available at: https://pdfs.semanticscholar. org/3fb2/0bf5aef29bb5741a78e3521c3536636e4635.pdf [Accessed: 12 October 2018]

[4] Claus, H. "Microbial Degradation of 2,4,6- Trinitrotoluene In Vitro and in Natural Environments", In: Singh, S. N. (ed.) Biological remediation of explosive residues, Springer International Publishing, Switzerland, pp. 15-38, 2014.

https://doi.org/10.1007/978-3-319-01083-0_2

[5] Chusova, O., Nolvak, H., Odlare, M., Truu, J., Truu, M., Oopkaup, K., Nehrenheim, E. "Biotransformation of pink water TNT on the surface of a low-cost adsorbent pine bark", Biodegradation, 26, pp. 375-386, 2015.

https://doi.org/10.1007/s10532-015-9740-7 years, microbial degradation and bioremediation of TNT has been attracted by many researchers as a cost-effective and environmentally friendly approach. Mostly, bioremediation of explosives has been studied for the discovery of microorganisms with high explosive degradation capacity to be inoculate into the bioreactor or directly contaminated area. Thus, many investigators have been isolated and identified microorganisms capable of metabolizing TNT to use in the bioremediation of TNT related compounds.

In this study, bacterial strains with high TNT degradation capacity were isolated from the TNT contaminated region in Turkey. The isolates obtained can be used safely and effectively in the bioreactors or directly contaminated regions, individually or with various bacterial consortia, for the purification of TNT contaminated sites. In addition, the isolates maintained their high TNT degradation capacity at a certain temperature and $\mathrm{pH}$ range. Especially, SU K3 isolate degraded TNT with high efficiency at different temperature. In addition, this isolate degraded more than $50 \%$ of the initial TNT, even in acidic or basic media. It is also envisaged that the use of these isolates in large-scale bioremediation processes will contribute to the development of an environmentally friendly and less costly method.

\section{Acknowledgement}

This study was financially supported by Kirikkale University Scientific Research Project Unit.

[6] Gümüşçü, B., Tekinay, T. "Effective biodegradation of 2,4,6-trinitrotoluene using a novel bacterial strain isolated from TNT-contaminated soil", International Biodeterioration \& Biodegradation, 85, pp. 35-41, 2013.

https://doi.org/10.1016/j.ibiod.2013.06.007

[7] Eum, J., Kwak, J., Kim, H.J., Ki, S., Lee, K., Raslan, A.A., Park, O.K., Chowdhury, M.A., Her, S., Kee, Y., Kwon, S.H., Hwang, B. J. "3D Visualization of Developmental Toxicity of 2,4,6-Trinitrotoluene in Zebrafish Embryogenesis Using LightSheet Microscopy", International Journal of Molecular Sciences, 17(11), pp. 1925, 2016.

https://doi.org/10.3390/ijms17111925

[8] Gallagher, E. M. "Anaerobic degradation of 2,4,6-trinitritoluene (TNT): molecular analysis of active degraders and metabolic pathways", PhD Thesis, The State University of New Jersey, New Jersey, 2010.

[9] Park, C., Kim, T.-H., Kim, S., Kim, S.-W., Lee, J., Kim, S.-H. "Optimization of biodegradation of 2,4,6-trinitrotoluene (TNT) by Pseudomonas putida", Journal of Bioscience and Bioengineering, 95, pp. 567-571, 2003. https://doi.org/10.1016/S1389-1723(03)80163-9

[10] Ayoub, K., van Hullebusch, E. D., Cassir, M., Bermond, A. "Application of advanced oxidation processes for TNT removal: A review", Journal of Hazardous Materials, 178(1-3), pp. 10-28, 2010. https://doi.org/10.1016/j.jhazmat.2010.02.042 
[11] Lewis, T. A., Newcombe, D. A., Crawford, R. L. "Bioremediation of soils contaminated with explosives", Journal of Environmental Management, 70, pp. 291-307, 2004. https://oi.org/10.1016/j.jenvman.2003.12.005

[12] Maleki, N. "Treatment and Biodegradation of High Explosives A Literature Review", PhD Thesis, University of California, Los Angeles, 1994.

[13] Oh, B. T., Sarah, G., Shea, P. J., Drijber, R. A., Comfort, S. D. "Rapid spectrophotometric determination of 2,4,6-trinitrotoluene in a Pseudomonas enzyme assay", Journal of Microbiological Methods, 42, pp. 149-158, 2000.

[14] Oh, S. Y., Yoon, H. S., Jeong, T. Y., Kim, S. D. "Evaluation of remediation processes for explosive-contaminated soils: Kinetics and Microtox ${ }^{\circledR}$ bioassay", Journal of Chemical Technology \& Biotechnology, 91, pp. 928-937, 2016. https://doi.org/10.1002/jctb.4658

[15] Lin, H., Yu, C., Chen, Z. "Aerobic and anaerobic biodegradation of TNT by newly isolated Bacillus mycoide", Ecological Engineering 52, pp. 270-277, 2013. https://doi.org/10.1016/j.ecoleng.2012.11.004

[16] Gümüş̧̧ü, B. "Bioremediation of 2,4,6-trinitrotoluene by Novel Strains of Aerobic Bacteria", MSc Thesis, Bilkent University, Ankara, 2012.

[17] Mercimek, H. A., Dincer, S., Guzeldag, G., Ozsavli, A., Matyar, F. "Aerobic biodegradation of 2,4,6-trinitrotoluene (TNT) by Bacillus cereus isolated from contaminated soil", Microbial Ecology, 66, pp. 512-521, 2013. https://doi.org/10.1007/s00248-013-0248-6

[18] Fuller, M. E., Manning, J. F. J. "Aerobic Gram-positive and Gramnegative bacteria exhibit differential sensitivity to and transformation of 2,4,6-trinitrotoluene (TNT)", Current Microbiology, 35, pp. 77-83, 1997. https://doi.org/10.1007/s002849900216

[19] Oh,K.H.,Kim,Y.J."Degradation ofExplosive2,4,6-Trinitroroluene by s-Triazine Degrading Bacterium Isolated from Contaminated Soil", Bulletin of Environmental Contamination and Toxicology, 61, pp. 702-708, 1998.

[20] Shin, J. H., Song, H. G. "Nitroreductase II involved in 2,4,6-trinitrotoluene degradation: purification and characterization from Klebsiella sp. C1", The Journal of Microbiology, 47, pp. 536-541, 2009.

https://doi.org/10.1007/s12275-008-0171-6

[21] Gün Gök, Z., İnal, M., Yiğitoğlu, M. "Effective Degradation of 2,4,6-Trinitrotoluene (TNT) with a Bacterial Consortium Developed from High TNT-degrading Bacteria Isolated from TNT-contaminated Soil", Hacettepe Journal of Biology and Chemistry, 46 (3), pp. 445-455, 2018. https://doi.org/10.15671/HJBC.2018.252

[22] Berg, G., Roskot, N., Smalla, K. "Genotypic and phenotypic relationships between clinical and environmental isolates of Stenotrophomonas maltophilia", Journal of Clinical Microbiology, 37 (11), pp. 3594-600, 1999.

[23] Podschun, R., Ullmann, U. "Klebsiella spp. as Nosocomial Pathogens: Epidemiology, Taxonomy, Typing Methods, and Pathogenicity Factors", Clinical Microbiology Reviews, 11, pp. 589-603, 1998.
[24] Kumar, H., Bhawanam "Development of Electrochemical Biosensor for the Detection of Klebsiella pneumoniae as Biological Weapon", Research Journal of Chemical Sciences, 5(12), pp. 88-97, 2015. [online] Available at: http://www.isca.in/rjes/Archives/v5/i12/9. ISCA-RJCS-2015-165.pdf [Accessed: 18 October 2018]

[25] Ma, C., Wang, A., Qin, J., Li, L., Ai, X, Jiang, T., Tang, H., Xu, P. "Enhanced 2,3-butanediol production by Klebsiella pneumoniae SDM", Applied Microbiology and Biotechnology, 82, pp. 49-57, 2009. https://doi.org/10.1007/s00253-008-1732-7

[26] Lu, X.Y., Ren, S.Y., Lu, J.Z., Zong, H., Song, J., Zhuge, B. "Enhanced 1,3-propanediol production in Klebsiella pneumoniae by a combined strategy of strengthening the TCA cycle and weakening the glucose effect", Journal of Applied Microbiology, 124, pp. 682-690, 2018 https://doi.org/10.1111/jam.13685

[27] Kalaria, S. S., Elliott, K., Combs, N., Phillips, L. G. "Raoultella planticola: A Rare Cause of Wound Infection", Wounds, 29 (11), pp. E103-E105, 2017.

[28] Bowman, N., Patel, D., Sanchez, A., Xu, W., Alsaffar, A., Tiquia-Arashiro, S. M. "Lead-resistant bacteria from Saint Clair River sediments and $\mathrm{Pb}$ removal in aqueous solutions", Applied Microbiology and Biotechnology, 102, pp. 2391-2398, 2018. https://doi.org/10.1007/s00253-018-8772-4

[29] Rahal, A. G., Moussa, L. A. "Degradation of 2,4,6-Trinitrotoluene (TNT) by Soil Bacteria Isolated From TNT Contaminated Soil", Australian Journal of Basic and Applied Sciences, 5(2), pp. 8-17, 2011

[30] Claus, H., Bausinger, T., Lehmler, I., Perret, N., Fels, G., Dehner, U., Preu $\beta$, J., König, H. "Transformation of 2,4,6-trinitrotoluene (TNT) by Raoultella terrigena", Biodegradation, 18(1), pp. $27-35,2007$ https://doi.org/10.1007/s10532-005-9033-7

[31] Maeda, T., Kadokami, K., Ogawa, H. I. "Characterization of 2,4,6-Trinitrotoluene (TNT)-Metabolizing Bacteria Isolated from TNT-Polluted Soils in the Yamada Green Zone, Kitakyushu, Japan", Journal of Environmental Biotechnology, 6(1), pp. 33-39, 2006. [online]. Available at: https://www.jseb.jp/wordpress/ wp-content/uploads/06-01-033.pdf [Accessed: 8 September 2018]

[32] Stenuit, B. A., Agathos, S. N. "Rapid and unbiased colorimetric quantification of nitrite and ammonium ions released from 2,4,6-trinitrotoluene during biodegradation studies: Eliminating interferences", International Biodeterioration \& Biodegradation, 63, pp. 116-122, 2009. https://doi.org/10.1016/j.ibiod.2008.09.001

[33] Küce, P., Coral, G., Kantar, Ç. "Biodegradation of 2,4-dinitrotoluene (DNT) by Arthrobacter sp. K1 isolated from a crude oil contaminated soil", Annals of Microbiology, 65, pp. 467-476, 2015. https://doi.org/10.1007/s13213-014-0880-5

[34] Habineza, A., Zhai, J., Mai, T., Mmereki, D., Ntakirutimana, T. "Biodegradation of 2, 4, 6-Trinitrotoluene (TNT) in Contaminated Soil and Microbial Remediation Options for Treatment", Periodica Polytechnica Chemical Engineering, 61(3), pp. 171-187, 2017. https://doi.org/10.3311/PPch.9251 